\title{
PENJADUALAN PRODUKSI MELALUI SISTEM PRODUKSI JUST IN TIME DENGAN KANBAN GUNA MEMENUHI PERMINTAAN
}

\author{
Eti Kristinawati ${ }^{1}$
}

\begin{abstract}
Just In Time production system is a production system which produce a product when they are needed and a fit number of product to achieve the consument's demand. To make the production process run well so it must be made a plan and schedule of good production process rangking which is approach with the demand condition.

CV. Sugih Waras is a furniture company which has a demand of product increase. This problem will make the company has trouble to achieve it. JIT production system with using a schedule of production and kanban become a problem solving alternetive to solve the customer demand problem. From the analysis we shown that using JIT problem system can reduce the back order of product result. The profit can be reached before implement JIT is Rp 253.236.000, 00 and after implement JIT is Rp 289.803.000,00 so that increase about Rp 36.567 .000 , 00 or $14.44 \%$.
\end{abstract}

\section{Key Words : JIT, Production Schedule, Kanban}

\section{PENDAHULUAN}

Dalam situasi persaingan global yang sangat kompetitif diperlukan adanya strategi produksi yang lebih baik bagi perusahaan dibandingkan dengan strategi produksi konvensional. Selain itu guna menghilangkan pemborosan perlu adanya aliran produksi kontinyu (stabil) yang dapat dilaksanakan melalui penerapan sistem produksi Just-In-Time melalui penjadwalan produksi dan kanban.

CV. Sugih Waras merupakan perusahaan yang bergerak dibidang furniture. Saat ini perusahaan mengalami kesulitan dalam pemenuhan permintaan konsumen akibat keterlambatan penyerahan produk. Hal ini disebabkan adanya perencanaan produksi yang kurang baik terhadap order yang diterima serta kurang ketatnya pengawasan terhadap jalannya produksi. Untuk itu diperlukan perbaikan pada urutan proses produksi dengan beban yang seimbang pada setiap lini. Sistem produksi Just-In-Time merupakan suatu solusi alternatif yang perlu diperhatikan serta dipertimbangkan bagi perusahaan untuk diterapkan sehingga perusahaan dapat menjaga kepercayaan konsumen.

\section{TINJAUAN PUSTAKA}

\section{SISTEM PRODUKSI TOYOTA}

Sistem produksi Toyota pertama kali dikembangkan dan dipromosikan oleh Toyota Motor Coorporation (TMC) dan telah dipakai oleh banyak perusahaan Jepang sebagai ekor krisis minyak ditahun 1973. 


\section{Tujuan Utama Sistem Produksi Toyota}

Tujuan utama sistem produksi

Toyota adalah pengurangan biaya atau perbaikan produktivitas dengan menghilangkan pemborosan.

Selain tujuan utama ada tiga sub tujuan yang harus dipenuhi, yaitu :

1. Pengendalian jumlah

2. Jaminan mutu

3. Menghormati kemanusiaan

\section{Dua Tiang Utama Sistem Produksi}

\section{Toyota}

1. Just-In-Time

2. Autonomasi.

\section{SISTEM PRODUKSI JUST IN TIME} (JIT)

Konsep dasar sistem produksi tepat waktu (Just-In-Time) adalah memproduksi produk yang diperlukan, pada waktu diperlukan dalam jumlah sesuai kebutuhan pada setiap tahap proses.

Pada dasarnya sistem produksi JIT mempunyai 6 tujuan dasar sebagai berikut:

1. Menurunkan ongkos manufakturing secara terus menerus.

2. Menghasilkan produk hanya berdasarkan permintaan pelanggan.

3. Menghasilkan produk berkualitas sesuai keinginan pelanggan.

4. Mengembangkan fleksibilitas manufakturing.

5. Mengintegrasikan dan mengoptimumkan setiap langkah pada proses manufakturing.
6. Mempertahankan komitmen tinggi untuk berkerja sama dengan pemasok dan pelanggan.

\section{SISTEM KANBAN}

Kanban merupakan kartu yang ditaruh dalam amplop vinil segi empat yang berisi tenteng informasi guna mencapai produksi Just In Time.

Dalam sistem produksi Toyota, sistem kanban didukung oleh :

1. Pelancaran produksi

2. Pembakuan pekerjaan (Operasi)

3. Pengurangan waktu sut-up

4. Autonomasi

5. Aktifitas perbaikan

6. Rancangan tata ruang mesin

\section{Klasifikasi Kanban :}

\section{Kanban Perintah Produksi}

* Kanban Produksi

* Kanban Segitiga

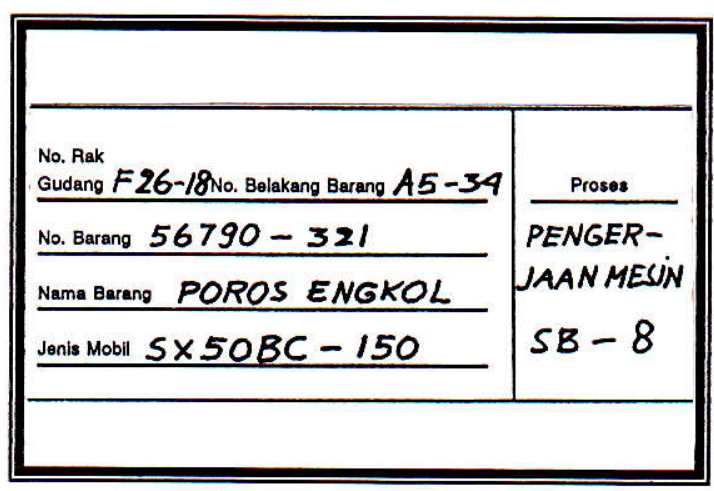

\section{Gambar 1}

Kanban Perintah Produksi

\section{Kanban Pengambilan}

* Kanban Pengambilan Antar Proses

* Kanban Pemasok 


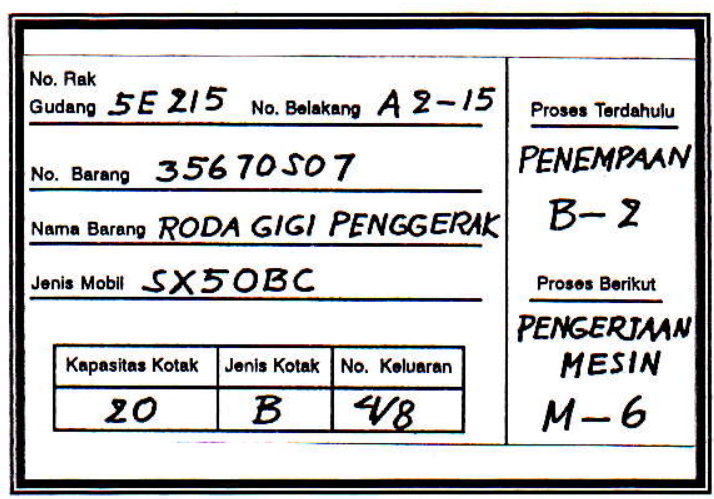

Gambar 2

Kanban Pengambilan

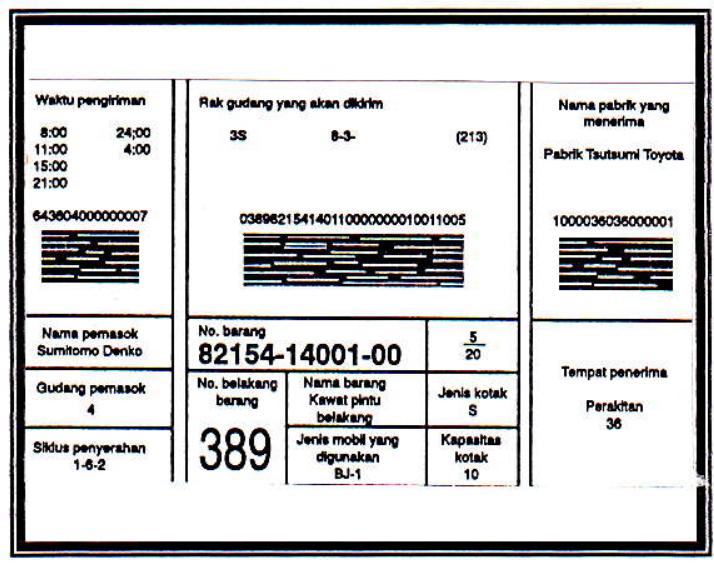

Gambar 3

Kanban Pemasok

\section{Peraturan Kanban}

* Proses berikutnya harus mengambil produk yang diperlukan dari proses terdahulu dalam jumlah yang diperlukan pada saat diperlukan.

* Proses terdahulu harus menghasilkan produk sesuai dengan jumlah yang diambil oleh proses berikutnya.

* Produk cacat tidak boleh diangkut pada proses berikutnya.

* Jumlah kanban harus sedikit mungkin

* Kanban harus digunakan untuk menyesuaikan terhadap fluktuasi kecil dalam permintaan.
Dalam jadwal urutan yang digunakan oleh pemasok diperlukan adanya :

* Informasi bulanan dan informasi harian

* Ruang penyimpanan dan variasi produk Produksi lancar membantu Toyota menyesuaikan diri pada perubahan permintaan dan mengurangi persediaan, melalui :

1. Perencanaan Produksi Bulanan

2. Pengiriman Produksi Harian

* Metode Penguruan Untuk Pelancaran Produksi

* Pengiriman Jadwal Urutan Ke Lini Assembling

\section{Penentuan Jumlah Kartu Kanban}

1. Sistem Pengambilan Jumlah Tetap Siklus Tidak Tetap

* Apabila set up (penyiapan) masih belum dilakukan dengan sempurna dan lot size besar.

$$
N=\frac{\left(\frac{D}{S}\right)+(d x \alpha)}{K}
$$

Dimana:

$$
\begin{aligned}
& \mathrm{N}=\text { Jumlah kanban } \\
& \mathrm{D}=\text { Demand bulanan } \\
& \mathrm{S}=\text { Jumlah penyiapan bulanan } \\
& \mathrm{d}=\text { Demand harian } \\
& \alpha=\text { Koefisien pengaman } \\
& \mathrm{K}=\text { Kapasitas kontainer }
\end{aligned}
$$

* Apabila set up (penyiapan) telah sempurna dan lot size kecil

$$
N=\frac{d \times W p \times(1+\alpha)}{K}
$$

dimana :

$$
W p=W o+W t+W k+W b
$$




$$
\begin{aligned}
& \mathrm{Wp}=\text { Apabila setup (penyiapan) } \\
& \mathrm{Wo}_{\mathrm{O}}=\mathrm{Waktu} \\
& \text { penyelesaian } \\
& \text { komponen pada proses } \\
& \text { terdahulu } \\
& \mathrm{Wt}=\text { Waktu menunggu sampai } \\
& \text { persediaan diambil oleh proses } \\
& \text { berikutnya } \\
& \mathrm{Wk}=\text { Waktu penyelesaian } \\
& \text { komponen oleh proses } \\
& \text { berikutnya } \\
& \mathrm{Wb}=\text { Waktu antara pengambilan } \\
& \text { kanban sampai dengan } \\
& \text { perintah produksi pada proses } \\
& \text { terdahulu. }
\end{aligned}
$$

\section{Sistem Pengambilan Siklus Tetap}

\section{Jumlah Tidak Tetap}

$$
N=\frac{d \times(c+W p+\alpha)}{K}
$$

dimana:

$$
\begin{aligned}
& \mathrm{N}=\text { Jumlah kanban } \\
& \mathrm{d}=\text { Demand harian } \\
& \mathrm{c}=\text { Siklus pemesanan } \\
& \mathrm{Wp}=\text { Waktu pemesanan } \\
& \alpha=\text { Koefisien pengamanan } \\
& \mathrm{K}=\text { Kapasitas kontainer }
\end{aligned}
$$

\section{Penentuan Jumlah Kartu Kanban}

\section{Pemasok}

$$
N=\frac{d \times(c+W p+\alpha)}{K}
$$

dimana :

$$
\begin{aligned}
& \mathrm{N}=\text { Jumlah keseluruhan kanban } \\
& \mathrm{d}=\text { Kebutuhan harian } \\
& \mathrm{c}=\text { Siklus pemesanan } \\
& \mathrm{Wp}=\text { Waktu pemesanan }
\end{aligned}
$$

$$
\begin{aligned}
& \alpha=\text { Koefisien pengaman } \\
& \mathrm{K}=\text { Kapasitas kontainer }
\end{aligned}
$$

\section{Langkah - langkah Metode Penjadwalan} Model Tetap

1. Menentukan jadwal produksi harian untuk model-model produk campuran.

2. Menentukan waktu siklus tiap produk.

3. Menentukan perbandingan waktu siklus tiap produk.

$$
\frac{1}{\text { WaktuSiklu } s A}, \frac{1}{\text { WaktuSiklu } s B}, \frac{1}{\text { WaktuSiklu } s C}
$$

4. Menentukan rasio dari jumlah total unit dalam deret terhadap waktu urutan.

5. Menentukan jadwal urutan.

\begin{tabular}{|c|c|c|c|c|}
\hline \multirow{2}{*}{ No } & \multicolumn{4}{|c|}{ Urutan } \\
\cline { 2 - 5 } & $\mathbf{1}$ & $\mathbf{2}$ & $\mathbf{3}$ & $\mathbf{4}$ \\
\hline 1 & A & B & A & C \\
\hline 2 & A & C & A & B \\
\hline 3 & A & B & C & A \\
\hline 4 & A & C & B & A \\
\hline 5 & B & A & C & A \\
\hline 6 & C & A & B & A \\
\hline
\end{tabular}

\section{METODOLOGI PENELITIAN}

\section{Jenis Data yang Diperlukan}

Adapun data yang diperlukan dalam penelitian ini adalah: jenis produk, mesin dan peralatan, proses operasi dan waktunya, data permintaan, data kapasitas produksi, lay out proses, serta data biaya produksi.

\section{Tahapan Pengolahan Data}

1. Peramalan / Forecast Demand

Hasil dari peramalan tersebut antara lain berguna untuk menghitung : 
Out Put Proses Perhari

Output per hari $=\frac{\text { Demand }(\text { forecast })}{\text { Hari } \text { ker ja dlmsatu } b \ln }$

\section{* Ukuran Lot Ekonomis}

Ukuranlot ekonomis $=\frac{\text { Jumlah demand }}{J m l \text { hari ker ja dlm satu bulan }}$

* Jumlah Kanban

2. Pembuatan Jadwal Urutan Proses

3. Pembuatan peredaran kanban

4. Membandingkan keuntungan sebelum dan sesudah penerapan sistem produksi Just In Time

\section{HASIL DAN PEMBAHASAN}

\section{Peramalan Jumlah Permintaan}

Pada peramalan permintaan digunakan bantuan software QS (Quantity System) dan dibantu dengan microsoft excell guna perhitungan MAPE yang mana nantinya akan dicari kesalahan yang terkecil ( MAPE < 10\%) untuk menentukan metode peramalan yang terbaik.

Tabel 1

Perbandingan MAD Dan MAPE

\begin{tabular}{|c|c|c|c|c|c|c|c|c|}
\hline \multirow{2}{*}{$\begin{array}{c}\text { Produ } \\
\text { k }\end{array}$} & \multicolumn{2}{|c|}{ Linear Regression } & \multicolumn{2}{c|}{ Simple Average } & \multicolumn{2}{c|}{ WMA M=3 } & \multicolumn{2}{c|}{ WMA M=5 } \\
\cline { 2 - 9 } & MAD & MAPE & MAD & MAPE & MAD & MAPE & MAD & MAPE \\
\hline A & 3.52 & 4.89 & 8.63 & 11.69 & 4.96 & 6.60 & 6.86 & 8.92 \\
\hline B & 5.42 & 4.91 & 20.11 & 15.82 & 12.15 & 9.87 & 19.77 & 15.36 \\
\hline C & 3.71 & 3.42 & 15.16 & 13.17 & 8.96 & 8.01 & 14.34 & 12.31 \\
\hline D & 3.80 & 5.29 & 13.22 & 16.23 & 7.44 & 10.57 & 9.31 & 12.46 \\
\hline
\end{tabular}

Dari forecast diatas, metode regresi linier merupakan metode terbaik untuk memproduksi produk A, B, C, dan D.

Tabel 2

Data Peramalan Permintaan Periode Juli 2001-Juni 2002

\begin{tabular}{|l|c|c|c|c|}
\hline \multirow{2}{*}{ Bulan } & \multicolumn{4}{|c|}{ Produk (unit ) } \\
\cline { 2 - 5 } & A & B & C & D \\
\hline Juli 2001 & 85 & 154 & 135 & 88 \\
\hline Agustus 2001 & 87 & 160 & 139 & 92 \\
\hline September 2001 & 90 & 166 & 144 & 95 \\
\hline Oktober 2001 & 92 & 172 & 148 & 99 \\
\hline November 2001 & 95 & 178 & 153 & 102 \\
\hline Desember 2001 & 97 & 184 & 157 & 106 \\
\hline Januari 2002 & 99 & 190 & 161 & 109 \\
\hline Febuari 2002 & 102 & 196 & 166 & 112 \\
\hline Maret 2002 & 104 & 202 & 170 & 116 \\
\hline April 2002 & 107 & 208 & 175 & 119 \\
\hline Mei 2002 & 109 & 214 & 179 & 122 \\
\hline Juni 2002 & 111 & 220 & 184 & 126 \\
\hline
\end{tabular}

Sedangkan jumlah part yang harus dibuat pada tiap departemen adalah sebagai berikut: 
Tabel 3

Jumlah Part yang Dibuat

\begin{tabular}{|l|c|c|c|c|c|c|c|c|c|c|c|c|}
\hline \multirow{2}{*}{ Departemen } & \multicolumn{4}{|c|}{ Juli2001 } & \multicolumn{3}{|c|}{ Agustus 2001 } & \multicolumn{3}{c|}{ Sept. 2001 } \\
\cline { 2 - 15 } & $\mathrm{A}$ & $\mathrm{B}$ & $\mathrm{C}$ & $\mathrm{D}$ & $\mathrm{A}$ & $\mathrm{B}$ & $\mathrm{C}$ & $\mathrm{D}$ & $\mathrm{A}$ & $\mathrm{B}$ & $\mathrm{C}$ & $\mathrm{D}$ \\
\hline Pembelahan & 1218 & 2198 & 2484 & 1620 & 1246 & 2282 & 2556 & 1692 & 1288 & 2366 & 2646 & 1746 \\
\hline Pemotongan & 1218 & 2198 & 2484 & 1620 & 1246 & 2282 & 2556 & 1692 & 1288 & 2366 & 2646 & 1746 \\
\hline Pembentukan & 1218 & 1884 & 2070 & 1350 & 1246 & 1956 & 2130 & 1410 & 1288 & 2028 & 2205 & 1455 \\
\hline $\begin{array}{l}\text { Penghalusan } \\
\text { Permukaan }\end{array}$ & 1218 & 2198 & 2484 & 1620 & 1246 & 2282 & 2556 & 1692 & 1288 & 2366 & 2646 & 1746 \\
\hline Bor & 174 & 471 & 552 & 360 & 178 & 489 & 568 & 376 & 184 & 507 & 588 & 388 \\
\hline Bubut & - & 314 & 414 & 270 & - & 326 & 426 & 282 & - & 338 & 441 & 291 \\
\hline Inspection & 552 & 1256 & 1656 & 1080 & 534 & 1304 & 1704 & 1128 & 552 & 1352 & 1764 & 1164 \\
\hline $\begin{array}{l}\text { Assemb. \& } \\
\text { Inspection }\end{array}$ & 261 & 471 & 414 & 270 & 267 & 489 & 426 & 282 & 276 & 507 & 441 & 291 \\
\hline $\begin{array}{l}\text { Pelapisan } \\
\text { (Dempul) }\end{array}$ & 87 & 157 & 138 & 90 & 89 & 163 & 142 & 94 & 92 & 169 & 147 & 97 \\
\hline Penyemprotan & 87 & 157 & 138 & 90 & 89 & 163 & 142 & 94 & 92 & 169 & 147 & 97 \\
\hline $\begin{array}{l}\text { Penghalusan } \\
\text { Amplas) }\end{array}$ & 87 & 157 & 138 & 90 & 89 & 163 & 142 & 94 & 92 & 169 & 147 & 97 \\
\hline Pengecatan & 87 & 157 & 138 & 90 & 89 & 163 & 142 & 94 & 92 & 169 & 147 & 97 \\
\hline Pengeringan & 87 & 157 & 138 & 90 & 89 & 163 & 142 & 94 & 92 & 169 & 147 & 97 \\
\hline $\begin{array}{l}\text { Pemasangan } \\
\text { Handle }\end{array}$ & 87 & 157 & 138 & 90 & 89 & 163 & 142 & 94 & 92 & 169 & 147 & 97 \\
\hline $\begin{array}{l}\text { Inspection Dan } \\
\text { Packing }\end{array}$ & 87 & 157 & 138 & 90 & 89 & 163 & 142 & 94 & 92 & 169 & 147 & 97 \\
\hline
\end{tabular}

Tabel 4

Waktu Siklus Produksi

\begin{tabular}{|c|c|c|c|c|}
\hline \multirow{2}{*}{$\begin{array}{c}\text { Periode } \\
\text { (2001) }\end{array}$} & \multicolumn{4}{|c|}{ Produk (Menit) } \\
\cline { 2 - 5 } & A & B & C & D \\
\hline Juli & 310.78 & 168.92 & 159.86 & 270.69 \\
\hline Agustus & 309.43 & 163.63 & 149.87 & 242.73 \\
\hline September & 284.43 & 146.73 & 143.61 & 235.35 \\
\hline
\end{tabular}

Tabel 5

Jadwal Urutan Proses Produksi Juli 2001

\begin{tabular}{|l|l|c|}
\hline Departemen & \multicolumn{1}{|c|}{ Urutan Produksi } & $\begin{array}{c}\text { Sehari } \\
\text { berulang }\end{array}$ \\
\hline Pembelahan & C-C-B-B-D-A & 12 kali \\
\hline Pemotongan & C-C-B-B-D-A & 12 kali \\
\hline Pembentukan & C-C-B-B-D-A & 12 kali \\
\hline $\begin{array}{l}\text { Penghalusan } \\
\text { Permukaan }\end{array}$ & C-C-B-B-D-A & 12 kali \\
\hline Bor & C-C-C-C-B-B-B-D-D-A & 2 kali \\
\hline Bubut & C-C-B-D & 4 kali \\
\hline Inspection & C-C-C-B-B-D-D-A & 5 kali \\
\hline $\begin{array}{l}\text { Assemb. \& } \\
\text { Inspection }\end{array}$ & B-B-C-C-A-D & 3 kali \\
\hline $\begin{array}{l}\text { Pelapisan } \\
\text { (Dempul) }\end{array}$ & B-B-C-C-A-D & 1 kali \\
\hline Penyemprotan & B-B-C-C-A-D & 1 kali \\
\hline $\begin{array}{l}\text { Penghalusan } \\
\text { (Amplas) }\end{array}$ & B-B-C-C-A-D & 1 kali \\
\hline Pengecatan & B-B-C-C-A-D & 1 kali \\
\hline Pengeringan & B-B-C-C-A-D & 1 kali \\
\hline $\begin{array}{l}\text { Pemasangan } \\
\text { Handle }\end{array}$ & B-B-C-C-A-D & 1 kali \\
\hline $\begin{array}{l}\text { Inspection Dan } \\
\text { Packing }\end{array}$ & B-B-C-C-A-D & 1 kali \\
\hline
\end{tabular}

\section{Tabel 6}

Jadwal Urutan Proses Produksi Agustus 2001

\begin{tabular}{|l|l|c|}
\hline Departemen & Urutan Produksi & $\begin{array}{c}\text { Sehari } \\
\text { berulang }\end{array}$ \\
\hline Pembelahan & C-C-B-B-D-A & 12 kali \\
\hline Pemotongan & C-C-B-B-D-A & 12 kali \\
\hline Pembentukan & C-C-B-B-D-A & 12 kali \\
\hline $\begin{array}{l}\text { Penghalusan } \\
\text { Permukaan }\end{array}$ & C-C-B-B-D-A & 12 kali \\
\hline Bor & C-C-C-B-B-B-D-D-A & 2 kali \\
\hline Bubut & C-C-B-D & 4 kali \\
\hline Inspection & C-C-C-B-B-D-D-A & 5 kali \\
\hline $\begin{array}{l}\text { Assemb \& } \\
\text { Inspection }\end{array}$ & B-B-C-C-A-D & 3 kali \\
\hline $\begin{array}{l}\text { Pelapisan } \\
\text { Dempul) }\end{array}$ & B-B-C-C-A-D & 1 kali \\
\hline Penyemprotan & B-B-C-C-A-D & 1 kali \\
\hline $\begin{array}{l}\text { Penghalusan } \\
\text { (Amplas) }\end{array}$ & B-B-C-C-A-D & 1 kali \\
\hline Pengecatan & B-B-C-C-A-D & 1 kali \\
\hline Pengeringan & B-B-C-C-A-D & 1 kali \\
\hline $\begin{array}{l}\text { Pemasangan } \\
\text { Handle }\end{array}$ & B-B-C-C-A-D & 1 kali \\
\hline $\begin{array}{l}\text { Inspection Dan } \\
\text { Packing }\end{array}$ & B-B-C-C-A-D & 1 kali \\
\hline
\end{tabular}


Tabel 7

Jadwal urutan proses produksi

September 2001

\begin{tabular}{|l|l|c|}
\hline \multicolumn{1}{|c|}{ Departemen } & \multicolumn{1}{c|}{ Urutan Produksi } & $\begin{array}{c}\text { Sehari } \\
\text { berulang }\end{array}$ \\
\hline Pembelahan & C-C-B-B-D-A & 13 kali \\
\hline Pemotongan & C-C-B-B-D-A & 13 kali \\
\hline Pembentukan & C-C-B-B-D-A & 13 kali \\
\hline $\begin{array}{l}\text { Penghalusan } \\
\text { Permukaan }\end{array}$ & C-C-B-B-D-A & 13 kali \\
\hline Bor & C-C-C-B-B-B-D-D-A & 2 kali \\
\hline Bubut & C-C-B-D & 4 kali \\
\hline Inspection & C-C-C-B-B-D-D-A & 6 kali \\
\hline $\begin{array}{l}\text { Assemb. \& } \\
\text { Inspection }\end{array}$ & B-B-C-C-A-D & 3 kali \\
\hline
\end{tabular}

\begin{tabular}{|l|l|c|}
\hline $\begin{array}{l}\text { Pelapisan } \\
\text { (Dempul) }\end{array}$ & B-B-C-C-A-D-D & 1 kali \\
\hline Penyemprotan & B-B-C-C-A-D & 1 kali \\
\hline $\begin{array}{l}\text { Penghalusan } \\
\text { (Amplas) }\end{array}$ & B-B-C-C-A-D & 1 kali \\
\hline Pengecatan & B-B-C-C-A-D & 1 kali \\
\hline Pengeringan & B-B-C-C-A-D & 1 kali \\
\hline $\begin{array}{l}\text { Pemasangan } \\
\text { Handle }\end{array}$ & B-B-C-C-A-D & 1 kali \\
\hline $\begin{array}{l}\text { Inspection Dan } \\
\text { Packing }\end{array}$ & B-B-C-C-A-D & 1 kali \\
\hline
\end{tabular}

Berdasarkan perhitungan didapat jumlah kanban tiap departemen sebagai berikut

Tabel 8

Jumlah Kanban Harian Tiap Departemen (unit )

\begin{tabular}{|l|c|c|c|c|c|c|c|c|c|c|c|c|}
\hline \multirow{2}{*}{ Departemen } & \multicolumn{3}{|c|}{ Juli2001 } & \multicolumn{3}{c|}{ Agustus 2001 } & \multicolumn{3}{c|}{ Sept. 2001 } \\
\cline { 2 - 12 } & A & B & C & D & A & B & C & D & A & B & C & D \\
\hline Pembelahan & 4 & 6 & 7 & 5 & 4 & 7 & 8 & 5 & 4 & 7 & 8 & 5 \\
\hline Pemotongan & 4 & 6 & 7 & 5 & 4 & 7 & 8 & 5 & 4 & 7 & 8 & 5 \\
\hline Pembentukan & 4 & 5 & 6 & 4 & 4 & 5 & 6 & 4 & 4 & 6 & 7 & 4 \\
\hline Penghalusan Permukaan & 4 & 6 & 7 & 5 & 4 & 7 & 8 & 5 & 4 & 7 & 8 & 5 \\
\hline Bor & 1 & 1 & 2 & 1 & 1 & 1 & 2 & 1 & 1 & 2 & 2 & 1 \\
\hline Bubut & - & 1 & 1 & 1 & - & 1 & 1 & 1 & - & 1 & 1 & 1 \\
\hline Inspection & 2 & 4 & 5 & 3 & 2 & 4 & 5 & 3 & 2 & 4 & 5 & 3 \\
\hline Assembling \& Inspection & 3 & 6 & 5 & 3 & 3 & 6 & 5 & 3 & 3 & 6 & 5 & 3 \\
\hline Pelapisan (Dempul) & 2 & 4 & 3 & 2 & 2 & 4 & 3 & 2 & 2 & 4 & 3 & 2 \\
\hline Penyemprotan & 2 & 4 & 3 & 2 & 2 & 4 & 3 & 2 & 2 & 4 & 3 & 2 \\
\hline Penghalusan (Amplas) & 2 & 4 & 3 & 2 & 2 & 4 & 3 & 2 & 2 & 4 & 3 & 2 \\
\hline Pengecatan & 2 & 4 & 3 & 2 & 2 & 4 & 3 & 2 & 2 & 4 & 3 & 2 \\
\hline Pengeringan & 2 & 4 & 3 & 2 & 2 & 4 & 3 & 2 & 2 & 4 & 3 & 2 \\
\hline Pemasangan Handle & 2 & 4 & 3 & 2 & 2 & 4 & 3 & 2 & 2 & 4 & 3 & 2 \\
\hline Inspection Dan Packing & 2 & 4 & 3 & 2 & 2 & 4 & 3 & 2 & 2 & 4 & 3 & 2 \\
\hline
\end{tabular}

Desain Profil Kartu Kanban

\begin{tabular}{|l|c|c|c|}
\hline $\begin{array}{l}\text { No. Rak. } \\
\text { Gudang: } \text { O-01 }\end{array}$ & $\begin{array}{c}\text { Proses Terdahulu: } \\
\text { Pembelahan }\end{array}$ \\
$\begin{array}{l}\text { No. Barang: 0-1 } \\
\text { Nama Barang: Tutup Almari AL-01 } \\
\text { Jenis Produk: T-AL 0-1 }\end{array}$ & $\begin{array}{c}\text { Proses Berikutnya: } \\
\text { Pemotongan }\end{array}$ \\
\hline Kapasitas Kotak & Jenis Kotak & No. Keluaran & \\
\hline 5 & A & $1 / 2$ & \\
\hline
\end{tabular}

Gambar 4

Profil Kanban Pengambilan 


\begin{tabular}{|l|l|}
\hline No. Rak. & Proses Terdahulu: \\
Gudang: O-01 & Pembelahan \\
No. Barang: 0-1 & \\
Nama Barang: Tutup Almari AL-01 & \\
Jenis Produk: T-AL 0-1 & \\
\hline
\end{tabular}

Gambar 5

Profil Kanban Perintah Produksi

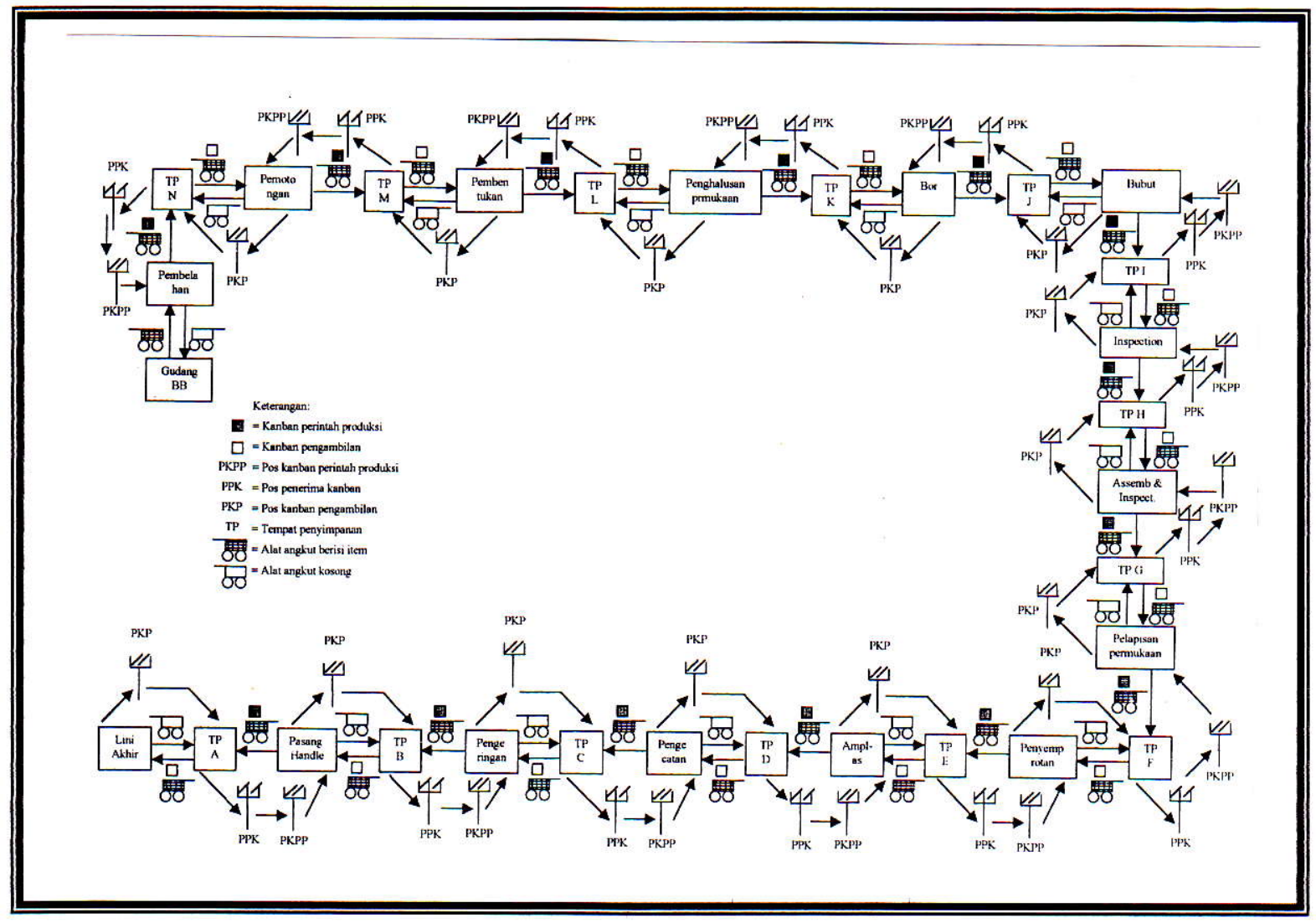

\section{Gambar 6 \\ Peredaran Sistem Kanban}

Perbandingan hasil produksi sebelum dan sesudah penerapan sistem Just-In-Time adalah :

Tabel 9

Perbandingan Hasil Produksi Sebelum Dan Sesudah

Penerapan Sistem Just-In-Time (Unit)

\begin{tabular}{|c|c|c|c|c|c|c|c|c|c|c|c|c|}
\hline \multirow[t]{2}{*}{ Bulan } & \multicolumn{4}{|c|}{ Permintaan } & \multicolumn{4}{|c|}{ Sebelum } & \multicolumn{4}{|c|}{ Sesudah } \\
\hline & $\mathbf{A}$ & B & C & D & $\mathbf{A}$ & B & C & D & $\mathbf{A}$ & B & $\mathrm{C}$ & D \\
\hline Juli 2001 & 85 & 154 & 135 & 88 & 81 & 146 & 144 & 76 & 87 & 157 & 138 & 90 \\
\hline Agustus2001 & 87 & 160 & 139 & 92 & 95 & 155 & 146 & 84 & 89 & 163 & 142 & 94 \\
\hline Sept. 200I & 90 & 166 & 144 & 95 & 103 & 152 & 138 & 87 & 92 & 169 & 147 & 97 \\
\hline
\end{tabular}


Dari tabel diatas maka dapat dicari total keuntungan yang diperoleh perusahaan untuk 3 periode terakhir yaitu Juli 2001, Agustus 2001, dan September 2001.

\section{* Total keuntungan sebelum penerapan} sistim Just-In_time

$=$ Keuntungan yang diperoleh ( Kehilangan keuntungan akibat kekurangan produksi + Kehilangan keuntungan akibat cacat produk + Biaya simpan akibat kelebihan produksi)

$$
\begin{aligned}
& =\operatorname{Rp} 275.101 .000,00- \\
& \text { (Rp 15.009.000,00 + } \\
& \text { Rp 5.931.000,00 + Rp 925.000,00) } \\
& =\operatorname{Rp} 253.236 .000,00
\end{aligned}
$$

\section{* Total keuntungan setelah penerapan} sistem Just-In-Time

$=$ Keuntungan yang diperoleh - Biaya simpan akibat kelebihan produksi

$=\operatorname{Rp} 290.553 .000,00-$ Rp 750.000,00

$=\operatorname{Rp} 289.803 .000,00$

* Peningkatan keuntungan yang diperoleh

$=$ Keuntungan sesudah JIT Keuntungan Sebelum JIT

$=\operatorname{Rp} 289.803 .000,00$ -

Rp 253.236.000,00

$=\operatorname{Rp} 36.567 .000,00$

\section{KESIMPULAN}

Dari analisa yang telah dilakukan dapat ditarik kesimpulan, antara lain :

1. Dengan menerapkan sistem produksi Just In Time (JT) melalui penjadwalan produksi dan kanban didapatkan jadwal produksi yang lebih baik dan terencana dibandingkan sebelumnya sehingga permintaan konsumen dapat dipenuhi secara tepat, baik dari segi waktu maupun jumlahnya.

2. Keuntungan yang diperoleh oleh perusahaan sebelum penerapan JIT sebesar Rp 253.236.000,00 dan setelah penerapan JIT keuntungan perusahaan sebesar Rp 289.803,00 sehingga mengalami peningkatan keuntungan sebesar Rp 36.567.000,00 atau peningkatan sebesar $14.44 \%$.

\section{DAFTAR PUSTAKA}

Asri, Marwan, Handoko, T. Hani dan Subagyo, 1984, Dasar-Dasar Riset Operasi, BPFE, Yogyakarta.

Monden, Yasuhiro, 1995, Sistem Produksi Toyota, Buku I dan II, PT. Pustaka Binaman Pressindo, Jakarta.

Ohno, Taichi, 1995, Just In Time dalam Sistem Produksi Toyota, PT. Pustaka Binaman Pressindo, Jakarta.

Schiederjans, Marc.J, 1992, Topics In JustIn Time Management, University of Nebrasca, Lincoln.

Marbun, B.N, 1984, Manajemen Jepang, PT. Pustaka Binaman Pressindo, Jakarta.

Suzaki, Kiyoshi, 1992, Tantangan Industri Manufaktur (Penerapan Perbaikan Berkesinambungan), Toyota Motor Corporation. 